Showa Univ. J. Med. Sci. 3(1), 11 17, June 1991

\title{
Original
}

\section{Effect of Curdlan, A Bacterial Water-Insoluble $\beta$-1,3-Glucan, on Experimental Escherichia coli Infection in Mice}

\author{
Hiroshi SAKagami ${ }^{1)}$, Masato FuJIMAKI ${ }^{2)}$, Chikako WADA ${ }^{2)}$ \\ and Nobuhiko Komatsu')
}

\begin{abstract}
Pretreatment with Curdlan, a water-insoluble (1-3)- $\beta$-D-glucan prepared from Alcaligenes faecalis var. myxogenes, IFO 13140, via an intraperitoneal route, significantly protected mice from lethal infection by various microorganisms. Introduction of a carboxymethyl group to Curdlan significantly increased its water-solubility, but almost completely eliminated its activity. Curdlan induced polymorphonuclear cell accumulation in the peritoneal cavity and generation of luminol-dependent chemiluminescence by peritoneal exudate cells. The chemiluminescence generated by macrophages was only $7 \%$ of that of total peritoneal exudate cells. The data suggest that the water-insolubility is an additional important factor that might affect antimicrobial activity induction.
\end{abstract}

Key words: Curdlan, water-insoluble glucan, antimicrobial activity, polymorphonuclear cell, chemiluminescence

\section{Introduction}

We investigated factors that might affect the induction of antimicrobial activity in mice, using various stimulators including antitumor polysaccharides, chemically-modified glucans, and lignin-related substances. The factors that significantly affected the induction of antimicrobial activity are: the molecular weight ${ }^{11}$, charge ${ }^{2)}$ and conjugation of lignin and other component(s) such as polysaccharide portion ${ }^{3,4)}$. We investigated whether water-insolubility is an additional factor influencing the induction of antimicrobial activity. A water insoluble (1-3)- $\beta$-D-glucan, Curdlan, isolated from Alcaligenes faecalis var. myxogenes, IFO 131405), and its water-soluble derivative (CM-Curdlan) $\left.{ }^{6}\right)$ were used for this purpose. These polysaccharides have been recognized for their host-mediated antitumor activity ${ }^{i, 8)}$, but have not been extensively studied for their ability to induce antimicrobial activity.

\section{Materials and Methods}

\section{Materials}

Curdlan (TAK) (DP540) ${ }^{5}$, prepared from Alcaligenes faecalis var. myxogenes, IFO 13140, and its carboxymethylated derivative (CM-Curdlan) ${ }^{6)}$ were kindly supplied by Takeda Chem. Ind., Ltd., Osaka. The molecular weight of Curdlan was determined by Manners' method ${ }^{9)}$ or by the GPC-LALLS method ${ }^{10)}$ (performed by Toray Research Laboratories).

\footnotetext{
1) First Department of Biochemistry, Showa University School of Medicine, 1-5-8 Hatanodai, Shinagawaku, Tokyo 142, Japan.

2) Public Welfare Institute of Scientific Research Foundation, 3-8-14, Nukuikitamachi, Koganei-shi, Tokyo 184, Japan.
} 
Mice

Female ICR mice (5 weeks old, 23-25 g) were obtained from Sankyo Laboratory Service Co., Tokyo. The mice were used at 6-7 weeks of age.

Antimicrobial activity

Each mouse was given a single injection of saline or Curdlan by the indicated injection route, $48 \mathrm{hr}$ before inoculation with about 1 minimum lethal dose of one of the following microorganisms: Escherichia coli GN2411 (obtained from the Department of Microbiology, School of Medicine, Gunma University), Pseudomonas aeruginosa H7 (obtained from the Institute of Medical Science, University of Tokyo), Klebsiella pneumoniae ST101 (obtained from the Department of Clinical Pathology, Showa University School of Medicine), Staphylococcus aureus SH10 (obtained from the Department of Clinical Pathology, Showa University School of Medicine) or Candida albicans YA2 (obtained from the Department of Clinical Pathology, Showa University Fujigaoka Hospital). Survival ratios were determined 1 week after inoculation with the first 4 strains of the microorganisms, or 3 weeks after inoculation with the last strain.

Peritoneal exudate cell collection and macrophage isolation

Mice were killed by decapitation and peritoneal fluid was withdrawn through a 22-gauge needle inserted into the cavity. The content of total polymorphonuclear cells (PMN) in the fluid was determined by the following formula: $P M N$ content $=A \times B$; where $A$ was the total cell number in the peritoneal fluid, determined with a hemocytometer, and B was the percent of PMN in all of the cells, assessed on a Cytospin slide (Shandon Southern Products Ltd., Astmoor, England) stained with May-Grunwald-Giemsa (Merck, Darmstadt, West Germany). For macrophage isolation, the peritoneal cells from 2 or 3 mice were cultured in $85-\mathrm{mm}$ Petri dishes (Iwaki) in $10 \mathrm{ml}$ of RPMI 1640 medium (GIBCO Laboratories, Grand Island, NY) supplemented with $10 \%$ fetal bovine serum (FBS) (Filtron Pty., Ltd., Brookyln, Australia). Macrophages were allowed to attach for $2 \mathrm{hr}$ at $37^{\circ} \mathrm{C}$ in a $5 \% \mathrm{CO}_{2}$ incubator. The plates were then washed three times with $0.9 \% \mathrm{NaCl}$ to remove nonadherent cells and the adherent macrophages were detached by scraping with a rubber policeman.

\section{Chemiluminescence assay}

The peritoneal exudate cells $\left(1 \times 10^{6}\right)$ were mixed with $1.25 \mathrm{mg}$ of opsonized zymosan A (Sigma, St. Louis, MO, USA) and $20 \mu \mathrm{g}$ luminol (Tokyo Kasei Kogyo Co., Ltd., Tokyo) in $0.6 \mathrm{ml}$ Eagle's MEM medium without phenol red (Nissui Pharm. Co., Ltd., Tokyo). Light emission was measured at $37^{\circ} \mathrm{C}$ immediately, and at 3 minute intervals over a 15 minute period, with the aid of an Aloka BLR-102 luminescence reader (Aloka Ltd., Tokyo) equipped with a controller. The chemiluminescence values were given as peak cpm rather than integral $\mathrm{cpm}^{11)}$.

\section{Results and Discussion}

\section{Antimicrobial activity of Curdlan}

When mice were inoculated with about $4 \times 10^{6}$ cells of Escherichia coli GN2411, only $17 \%$ survived after 1 day (Fig. 1). However, if pretreated intraperitoneally with $0.4,2$ or $8 \mathrm{mg} / \mathrm{kg}$ Curdlan 2 days before the $E$. coli challenge, the survival rates increased to 60 , 100 and $100 \%$, respectively (Fig. 1).

\section{Effect of injection route}

Table 1 shows that injection of Curdlan via the intraperitoneal route induced the highest 


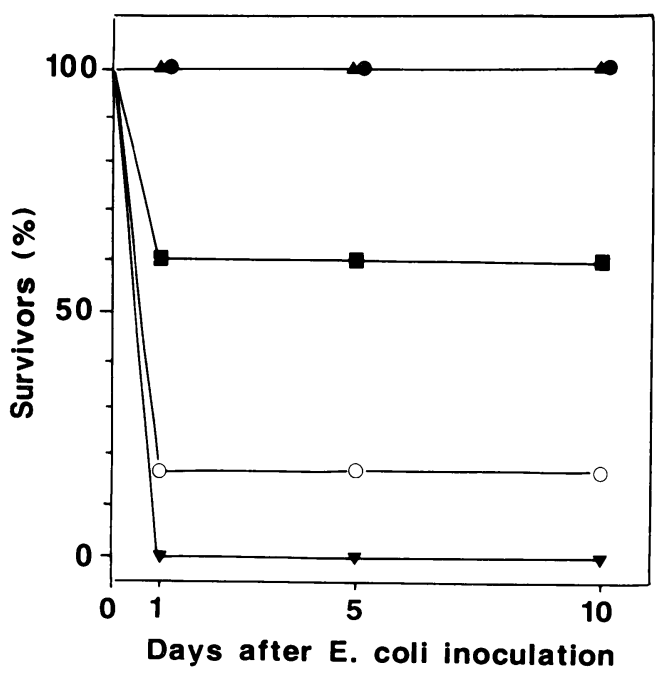

Fig. 1. Dose-dependent inhibition of Escherichia coli infection by Curdlan injection. Mice (10-12/group) were intraperitoneally injected with $0(\bigcirc), 0.08(\nabla), 0.4(\boldsymbol{\square}), 2(\Delta)$ or $8(\bullet) \mathrm{mg} / \mathrm{kg}$ Curdlan, $48 \mathrm{hr}$ before $E$. coli challenge. Survival rates were determined at the indicated days after $E$. coli challenge.

Table 1. Protective activity of Curdlan against Escherichia coli infection.

\begin{tabular}{|c|c|c|c|}
\hline \multicolumn{2}{|c|}{ Dose $(\mathrm{mg} / \mathrm{kg})$} & Injection route of Curdlan & \multirow{2}{*}{$\frac{\text { No. of survivors }}{10 / 10}$} \\
\hline Exp. I: & 8 & i.p. & \\
\hline & 0 (control) & - & $2 / 12$ \\
\hline \multirow[t]{3}{*}{ Exp. II: } & 8 & s.c. & $2 / 10$ \\
\hline & 8 & i.m. & $3 / 10$ \\
\hline & 0 (control) & - & $2 / 12$ \\
\hline \multirow[t]{2}{*}{ Exp. III: } & 8 & i.v. & toxic \\
\hline & 0 (control) & - & $2 / 12$ \\
\hline
\end{tabular}

Mice (10-12/group) were injected with one dose of saline (control) or Curdlan by the indicated routes $48 \mathrm{hr}$ before $E$. coli inoculation. Survival ratio was determined 1 week after $E$. coli inoculation. $E$. coli was used for this experiment, since this microorganism was found to be the most sensitive to Curdlan among 5 different microorganisms (Table 2).

antimicrobial activity against $E$. coli (Exp. I), whereas subcutaneous or intramuscular injection was ineffective (Exp. II). The intravenous injection was toxic (Exp. III). Antimicrobial spectrum of Curdlan

We next investigated the antimicrobial spectrum of Curdlan, using three Gram negative rods (Escherichia coli GN2411, Pseudomonas aeruginosa H7, Klebsiella pneumoniae ST101), one Gram positive coccus (Staphylococcus aureus SH10) and one Fungus (Candida albicans YA2). These microbials, except for the Gram positive coccus, might be important to the study of the opportunistic infection observed during an immunosuppressive state. 
Table 2. Antimicrobial spectrum of Curdlan.

\begin{tabular}{|c|c|c|c|c|}
\hline Microorganisms & $\begin{array}{l}\text { (Number of cells } \\
\text { inoculated per mouse) }\end{array}$ & $\begin{array}{l}\text { Route of } \\
\text { inoculation }\end{array}$ & $\begin{array}{l}\text { Injection dose of } \\
\text { Curdlan }(\mathrm{mg} / \mathrm{kg})\end{array}$ & $\begin{array}{l}\text { No. of } \\
\text { Survivors }\end{array}$ \\
\hline \multicolumn{5}{|l|}{ Gram negative rod: } \\
\hline \multirow[t]{5}{*}{ Escherichia coli GN2411 } & $\left(4 \times 10^{8}\right)$ & i.p. & 0 & $2 / 12$ \\
\hline & & & 0.08 & $0 / 10$ \\
\hline & & & 0.4 & $6 / 10$ \\
\hline & & & 2 & $10 / 10$ \\
\hline & & & 8 & $10 / 10$ \\
\hline \multirow[t]{5}{*}{ Pseudomonas aeruginosa $\mathrm{H} 7$} & $\left(8 \times 10^{7}\right)$ & i.p. & 0 & $0 / 10$ \\
\hline & & & 0.08 & $0 / 10$ \\
\hline & & & 0.4 & $2 / 10$ \\
\hline & & & 2 & $5 / 10$ \\
\hline & & & 8 & $6 / 10$ \\
\hline \multirow[t]{5}{*}{ Klebsiella pneumoniae ST101 } & $\left(2.5 \times 10^{8}\right)$ & i.p. & 0 & $1 / 12$ \\
\hline & & & 0.08 & $2 / 10$ \\
\hline & & & 0.4 & $2 / 10$ \\
\hline & & & 2 & $2 / 10$ \\
\hline & & & 8 & $4 / 10$ \\
\hline \multirow{6}{*}{$\begin{array}{l}\text { Gram positive coccus: } \\
\text { Staphylococcus aureus } \mathrm{SH} 10\end{array}$} & & & & \\
\hline & $\left(1 \times 10^{9}\right)$ & i.p. & 0 & $0 / 10$ \\
\hline & & & 0.08 & $0 / 10$ \\
\hline & & & 0.4 & $1 / 10$ \\
\hline & & & 2 & $5 / 10$ \\
\hline & & & 8 & $10 / 10$ \\
\hline \multicolumn{5}{|l|}{ Fungus: } \\
\hline \multirow[t]{5}{*}{ Candida albicans YA2 } & $\left(1 \times 10^{7}\right)$ & i.v. & 0 & $0 / 10$ \\
\hline & & & 0.08 & $0 / 10$ \\
\hline & & & 0.4 & $0 / 10$ \\
\hline & & & 2 & $0 / 10$ \\
\hline & & & 8 & $2 / 10$ \\
\hline
\end{tabular}

Mice (10-12/group) were intraperitoneally injected with saline (control) or the indicated doses of Curdlan, $48 \mathrm{hr}$ before inoculation of the indicated numbers of cells of each microorganism (in parenthesis) via the indicated routes. Survival ratio was determined 1 week after inoculation with the first 4 strains of the microorganisms, and 3 weeks after inoculation with Candida albicans.

Pretreatment of mice with Curdlan, via an intraperitoneal route, significantly reduced the lethal effects of various microorganisms including Escherichia coli, Pseudomonas aeruginosa H7 and Staphylococcus aureus SH10 (Table 2). The effect of Curdlan against these microorganisms was observed at doses higher than $0.4-2 \mathrm{mg} / \mathrm{kg}$. However, Curdlan was only marginally effective against Klebsiella pneumoniae ST101, and it was totally ineffective against Candida albicans YA2. We inoculated Candida albicans by the intravenous route, because of the higher lethality of this route (data not shown).

Effect on peritoneal cells

Intraperitoneal injection of Curdlan induced significant accumulation of polymorphonuclear cells (PMN) (Fig. 2A) and stimulated the generation of luminol-dependent chemiluminescence (LDCL) by peritoneal exudate cells (Fig. 2B). The increases in PMN number and in LDCL 

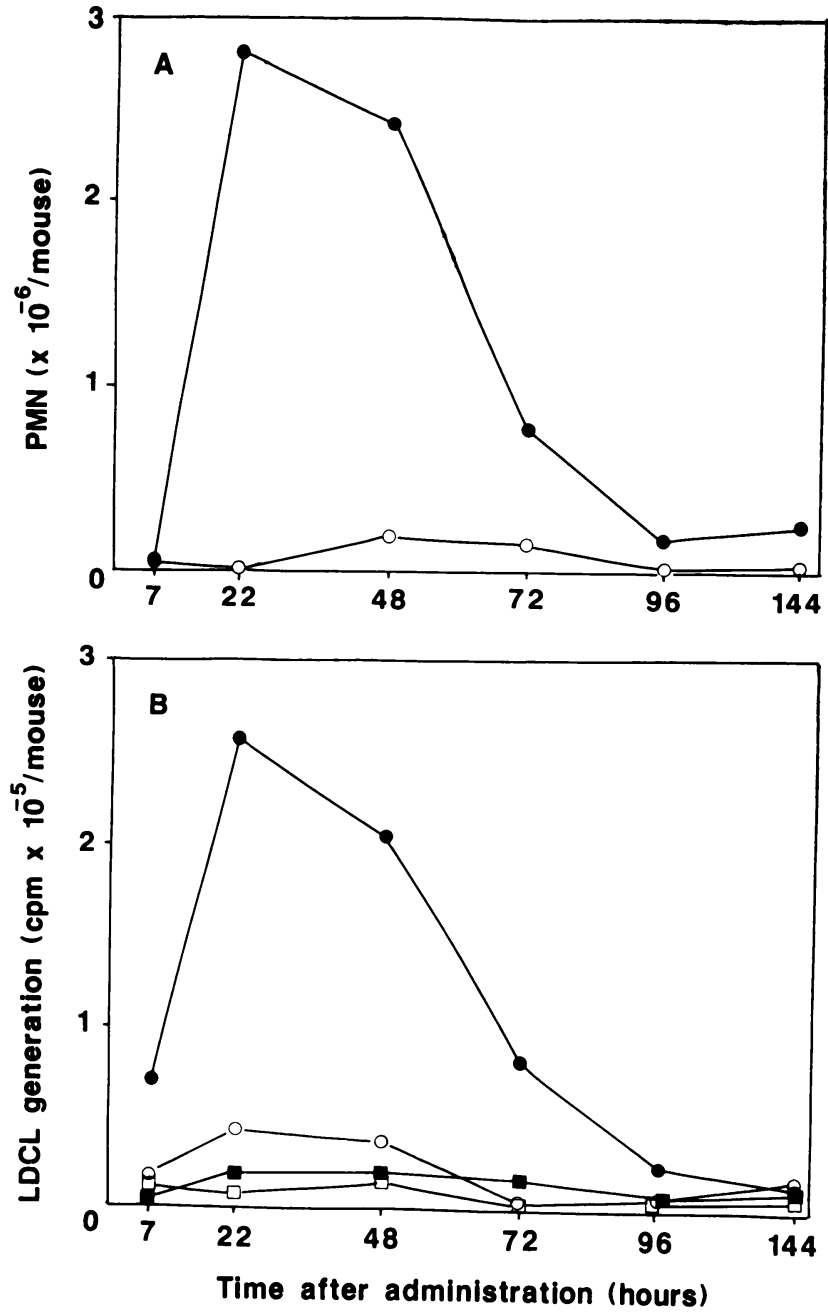

Fig. 2. (A) Time course of $P M N$ accumulation in the peritoneal cavity after intraperitoneal injection with $0(O)$ or $8(\bullet) \mathrm{mg} / \mathrm{kg}$ Curdlan. (B) Time course of LDCL generation by total $(O)$ and adherent $(\square)$ peritoneal exudate cells after intraperitoneal injection of saline, and time course of LDCL generation by total ( $\bullet$ ) and adherent ( $\square$ ) peritoneal exudate cells after intraperitoneal injection of $8 \mathrm{mg} / \mathrm{kg}$ Curdlan. Each value is mean from 2 mice. S.D. $<20 \%$.

generation by peritoneal exudate cells were superimposed on each other, peaking at $22 \mathrm{hr}$ after Curdlan injection and then declining to control level at $144 \mathrm{hr}$.

Most of the mice died within 1 day after intraperitoneal inoculation of $E$. coli, but the intraperitoneal injection of Curdlan at the same site (peritoneal cavity) significantly reduced the lethal effect of $E$. coli inoculation (Fig. 1). Since Curdlan induced rapid accumulation of PMN, which had higher LDCL generating activity (Fig. 2), it is highly probable that Curdlaninduced PMN might be responsible for the rapid disappearance of $E$. coli, especially in the early stages (0-24 hr) after Curdlan injection. The contribution of macrophages for antimicrobial activity induction by Curdlan seems low, since the LDCL generation by adherent 
Table 3. Inability of antimicrobial activity induction by water-soluble CM-Curdlan.

\begin{tabular}{lccc} 
Sample & Water solubility & $\begin{array}{c}\text { No. of PMNa }) \\
\left(\times 10^{-5} / \text { mouse }\right)\end{array}$ & $\begin{array}{c}\text { Antimicrobialb) } \\
\text { activity }\end{array}$ \\
\cline { 4 - 4 } & & $0.8 \pm 0.2$ & No. of survivors \\
\hline None (control) & + & $4.6 \pm 0.5$ & $2 / 12$ \\
CM-Curdlan & - & $16.0 \pm 1.6$ & $1 / 10$ \\
Curdlan & & $10 / 10$
\end{tabular}

a) Mice ( $3 \mathrm{mice} /$ group) were intraperitoneally injected with saline (control) or $8 \mathrm{mg} / \mathrm{kg}$ of each sample. After $48 \mathrm{hr}$, the peritoneal exudate was withdrawn and the number of PMN was determined. Each value is mean \pm S.E. from 3 mice.

b) Mice (10-12/group) were intraperitoneally injected with one dose of saline (control) or $8 \mathrm{mg} / \mathrm{kg}$ of each sample, $48 \mathrm{hr}$ before $E$. coli inoculation. Survival ratio was determined 1 week after $E$. coli inoculation.

macrophages of Curdlan-treated mice was less than $10 \%$ of that of total peritoneal exudate cells (Fig. 2B).

When a carboxymethyl group was introduced to the Curdlan to improve its water-solubility, its ability to induce PMN accumulation and antimicrobial activity was significantly reduced (Table 3). This indicates that the water-insolubility is an additional important factor that affects the induction of antimicrobial activity.

\section{Acknowledgments}

We thank Dr. A. Simpson for help with the manuscript. This study was supported in part by the SHORAI Foundation for Science and Technology.

\section{References}

1) Harada H, Sakagami H, Konno K, Sato T, Ohsawa N, Fujimaki M and Komatsu N: Antimicrobial activity induction by PSK subfractions: Dependence on molecular weight. Infection, 17: 38-39 (1989)

2) Sakagami H, Unten S, Hanaoka A, Ohsawa N, Fujimaki M, Komatsu N, Ichikawa S, Hata N, Kondo $\mathbf{H}$ and Konno $\mathrm{K}$ : Chemical modification potentiates paramylon induction of antimicrobial activity. In Vivo, 3: 243-248 (1989)

3) Oh-hara T, Sakagami H, Kawazoe Y, Momoi T, Kaiya T, Kohda K, Komatsu N, Ohsawa N, Fujimaki $M$ and Konno K: Lignified materials as potential medicinal resources. II. Prevention of pathogenic bacterial infections in mice. In Vivo, 4: 221-224 (1990)

4) Oh-hara T, Kawazoe $Y$ and Sakagami H: Lignified materials as potential medicinal resources. III. Diversity of biological activity and possible molecular species involved. Chem Pharm Bull, 38: 30313034 (1990)

5) Harada T, Misaki A and Saito H: Curdlan: A bacterial gel-forming $\beta$-1,3-glucan. Arch Biochem Biophys, 124: 292-298 (1968)

6) Sasaki T, Abiko N, Nitta K, Takasuka N and Sugino Y: Antitumor activity of carboxymethylglucans obtained by carboxymethylation of (1-3)- $\beta$-D-glucan from Alcaligenes faecalis var. myxogenes, IFO 13140. Eur J Cancer, 15: 211-215 (1979)

7) Sasaki T, Abiko N, Sugino $Y$ and Nitta K: Dependence on chain length of antitumor activity of (1-3)- $\beta$-D-glucan from Alcaligenes faecalis var. myxogenes, IFO 13140, and its acid-degraded products. Cancer Res, 38: 379-383 (1978)

8) Kunimoto T, Baba $\mathrm{H}$ and Nitta $\mathrm{K}$ : Antitumor polysaccharide-induced tumor-regressing factor in the serum of tumor-bearing mice: Purification and characterization. J Biol Response Mod, 5: 225-235 (1986) 
9) Manners DJ, Masson AJ and Sturgeon RJ: An enzymic method for the determination of the degree of polymerization of glucans. Carbohyd Res, 17: 109-114 (1971)

10) Matsumura G: Viscosity, ultracentrifugation and light scatter. In: Seikagaku Jikken Koza IV. (part II). Chemistry of Carbohydrate, Yamashina I, Yamakawa T, Suzuki S (Ed), Tokyo Kagaku Dojin, Tokyo, pp 441-462 (1976) (in Japanese)

11) Harada H, Sakagami H, Konno K, Sato T, Ohsawa N, Fujimaki $M$ and Komatsu $N$ : Induction of antimicrobial activity by antitumor substances from pine cone extract of Pinus parviflora Sieb. et Zucc. Anticancer Res, 8: 581-588 (1988)

[Received November 8, 1990: Accepted December 10, 1990] 